\title{
EDUCAÇÃO AMBIENTAL EM CENTROS URBANOS: RELATO DE UMA eXPeriência no ensino público de Curitiba, Paraná ${ }^{1}$
}

\section{Environmental education in urban centers: a word about an experience in public education in Curitiba, Paraná State Educación medioambiental en centros urbanos: informe
de una experiencia en la enseñanza pública en
Curitiba, Estado do Paraná}

\author{
Fábio Maciel Pinto ${ }^{2}$ \\ Felipe Brasil Felício ${ }^{2}$ \\ Eduardo Roemers de Oliveira ${ }^{2}$ \\ Anderson L. G. Belem² \\ Bruno W. Jeiss ${ }^{2}$ \\ Marcell Leonard Besser ${ }^{2}$ \\ João Eloi Dums² \\ Luiz Alberto Fernandes ${ }^{3}$
}

\begin{abstract}
RESUMO
Este relato apresenta experiência de educação ambiental, realizada em 2006 pelo grupo PET-Geologia da Universidade Federal do Paraná (UFPR). Na ocasião foi escolhida uma turma de sexta série do ensino fundamental do Colégio Estadual Hildebrando de Araújo, de Curitiba. O desenvolvimento dos trabalhos apoiou-se em atividades lúdicas e material audiovisual para melhor interação com os alunos, de modo a oferecer atividades em sala de aula, num formato não usual no ensino do colégio. Questões do cotidiano urbano foram integradas ao conteúdo técnico-científico apresentado à turma. A assimilação dos conceitos pelos estudantes foi grande e os resultados positivos. As principais dificuldades verificadas durante a experiência foram: falta de noção dos alunos sobre o que é espaço geográfico, seu pouco conhecimento sobre a importância do uso racional do ambiente e necessidade de reforço na formação continuada de alguns professores em relação aos temas propostos.
\end{abstract}

Palavras-chave: Educação ambiental; Ensino fundamental; Ensino público; Curitiba; PET.

\begin{abstract}
This paper describes an experience in the environmental education field, that happened in 2006, concerning the PET-Geologia group from the Federal University of Paraná. In that occasion, a sixth grade class was chosen from the Hildebrando de Araújo School, of Curitiba. The project's development was based on ludic activities and audiovisual resources, in order to better interact with the students and offer a non-usual approach in teaching. Technical-scientific content was integrated with urban life issues and presented to the class. All the subjects were well absorbed by the students. The main difficulties in the project were poor notion of the students about geographic space, as well as their lack of knowledge about the importance
\end{abstract}

\footnotetext{
1 Correspondência para/ Correspondence to Universidade Federal do Paraná, Setor de Ciências da Terra, PET-Geologia - $81.531-990$ - Curitiba, PR - Brasil - Caixa postal: 19.001 Fone: (41) 3361-3245/3361-3386 FAX: (41) 3361-3163. E-mail: pet.geologia@ufpr.br/ petgeo.ufpr@gmail.com.

2 Integrante PET (Programa de Educação Tutorial/MEC-SESU).

$3 \quad$ Tutor PET. E-mail: lufernandes@ufpr.br.

Experiência financiada pela PETROBRAS e registrada na Pró-reitoria de extensão e cultura da UFPR sob o número 399/06-PROEC.
} 
of the environmental consciousness in using nature's resources, and the necessity of a reinforcement of a continuous training of teachers on the related subjects.

Keywords: Environmental education; Primary education; Public education; Curitiba; PET.

\section{RESUMEN}

Este relato presenta una experiencia de educación ambiental realizada en el 2006 por el grupo PET-Geología de la Universidade Federal do Paraná. Para dicha experiencia fue elegida una clase de sexto año de enseñanza fundamental del Colegio Estatal Hildebrando de Araújo, de Curitiba (Paraná-Brasil). En los trabajos se utilizaron actividades lúdicas y material audiovisual para interrelacionarse mejor con los alumnos, ofreciéndoles actividades en clase en una forma diferente a aquella enseñanza practicada en la escuela. Cuestiones del cotidiano urbano fueron integradas al contenido científico presentado. La asimilación de los conceptos por los estudiantes fue grande y los resultados positivos. Las principales dificultades verificadas durante la experiencia fueron la falta de noción de los alumnos sobre su espacio geográfico, el poco conocimiento sobre la importancia del uso racional del ambiente y la necesidad de refuerzo en la formación continuada de algunos de los profesores en relación a los temas propuestos.

Palabras-clave: Educación ambiental; Educación primaria; La educación pública; Curitiba; PET.

\section{Introdução}

Atualmente, a consciência do uso racional do meio em que vivemos é cada vez mais necessária. Compreender e respeitar limites e aptidões do planeta constitui parte fundamental da educação para o desenvolvimento da cidadania e da gestão ambiental para qualidade de vida.

Problemas ambientais em centros urbanos podem ter causas naturais ou serem provocados pelo homem. A ação antrópica pode contribuir para desequilibrar e/ou acelerar processos naturais que afetam a vida nas cidades. Enchentes, escorregamentos, erosão, contaminação de rios, lagos, do solo e das águas são alguns exemplos.

$\mathrm{O}$ ambiente incorpora as concepções de natureza e sociedade e as relações e dependências entre ambas, assim, quando se fala de degradação ambiental significa falar de questões sociais e ambientais. O ser humano necessita dos recursos naturais para sua subsistência. No entanto a natureza também tem limites que não devem ser ultrapassados (MOTA, 1999). Para que as populações possam entender essa relação entre homem e natureza, comedir a instabilidade no meio natural, agravada nas últimas décadas, é necessário um trabalho de educação que contemple tais questões.
As cidades, objeto de aplicação da experiência que será relatada, também fazem parte do meio ambiente. Trata-se do habitat da espécie humana (e de muitas outras que se adaptaram) e está inserida na ecologia do planeta, sendo, por muitos pesquisadores, considerada um Ecossistema. No entanto, o que se vê é uma distinção de natureza e sociedade. Assim, as pessoas podem compreender que não existe natureza na cidade e que, portanto, não há necessidade de condições de qualidade ambiental dentro das mesmas, o que, segundo Nucci (1999), não é verdade, pois dentre as necessidades do ser humano pode-se citar: ar fresco, água limpa, espaços de descanso, entre outras que com a natureza dentro da cidade podem ser melhoradas.

O trabalho com temas ambientais, relacionados às áreas urbanas onde vive o ser humano e ao seu cotidiano, é um caminho eficaz para iniciar discussões, aprendizado e criar espírito critico sobre os problemas ambientais, buscando formas de prevenção e soluções.

O PET-Geologia da Universidade Federal do Paraná (UFPR), grupo integrante do Programa de Educação Tutorial mantido pelo Ministério da Educação, há alguns anos implementa projetos de extensão que visam auxiliar na formação do cidadão consciente da sua importância para o ambiente social $e$ 
natural. Em 2006, a proposta de um projeto de educação ambiental que abrangeria discussões $e$ trabalhos sobre questões socioambientais regionais, levou o grupo a analisar o tema e alternativas de como aplicá-lo, sem que a inserção de conceitos se tornasse maçante, possibilitando a fácil assimilação pelo públicoalvo. Na época de execução do projeto, o público era formado por alunos da sexta série, turma A, do ensino fundamental do Colégio Hildebrando de Araújo, localizado em Curitiba, no bairro Jardim Botânico. O relato a seguir é fruto dessa experiência com educação ambiental, desenvolvida no período de fevereiro de 2006 a fevereiro de 2007.

\section{Histórico}

Entre 2002 e 2003 o PET-Geologia realizou sua primeira experiência com educação ambiental (MESQUITA et al., 2006). Na ocasião, o grupo foi convidado pela Secretaria Municipal de Ação Social de Rio Branco do Sul - Região Metropolitana de Curitiba, Paraná - para elaborar e executar um projeto com jovens em situação de risco social, com idades entre 15 e 17 anos. Tal projeto abordou questões sobre a constituição da Terra, processos geológicos, contaminação de águas superficiais e subterrâneas. O foco principal foi o estado de conservação e medidas de proteção de cavernas daquele município. Em 2005, interessado pelo ensino das Geociências em escolas, o PET-Geologia optou por nova experiência educacional, desta vez com estudantes do ensino médio da rede pública, do Colégio Prof. Júlio Mesquita, em Curitiba. A proposta de trabalho foi incentivar os estudantes a questionar-se sobre o ambiente urbano em que viviam, em especialmente o bairro da escola, no que nele há de bom e ruim, "natural" ou causado pela ação humana. Por fim, para apresentação e discussão dos conceitos de processos naturais, contextualização geográfica e social, problemas e soluções, os estudantes construíram uma maquete do bairro em que se localiza a escola (JUK et al., 2006).

\section{Objetivos}

O projeto teve por objetivo aumentar a sensibilidade e conhecimento, para desenvolver a consciência ecológica e princípios de cidadania dos alunos. Buscou-se, igualmente, transmitir conceitos básicos de Geociências, para suprir deficiência do modo de abordagem no ensino fundamental brasileiro, conforme Matz; Araujo et al. descreveram (2006). A instituição de ensino escolhida para o desenvolvimento, foi o Colégio Estadual Hildebrando de Araújo, com atividades orientadas da escala local para a regional, afeitas ao cotidiano dos estudantes: a rua, a escola, o bairro, a cidade. Assim, identificou-se e discutiu os problemas ambientais locais, seus efeitos $e$ propostas de soluções adequadas.

\section{Materiais e métodos}

A experiência criou oportunidades didáticas de identificação, análise e compreensão de problemas ambientais das proximidades de escolas em áreas urbanas. Esses, decorrentes de ocupação inadequada do território, mau uso $e$ contaminação da água, eventos naturais e ação antrópica. Desenvolveu-se, ainda, a observação e a sensibilidade para características do meio físico no âmbito desses problemas.

Em acordo estabelecido com o colégio, decidiu-se realizar encontros semanais, de 50 minutos cada, para desenvolvimento do projeto. Os encontros ocorreram durante aulas da disciplina de Geografia à turma sexta 
série A. Os trinta e cinco alunos participantes, de idades entre doze e quinze anos, residiam no bairro em que se localiza o colégio ou em bairros vizinhos.

Foram previstos treze encontros, com atividades que abrangiam os temas: meio natural, homem e meio urbano, lixo, água, seres vivos, energia e poluição, problemas mundiais de ordem regional e global.

Para aplicar os conceitos referentes aos temas, optou-se pelo uso de materiais de caráter lúdico e audiovisual. Esse procedimento visou colocar os alunos em contato concreto com os temas, ao mesmo tempo em que as atividades fossem conduzidas num clima descontraído, de "passatempo". Para complementar a assimilação dos conceitos, se deu enfoque ao trabalho prático e saídas a campo. Desse modo, os alunos ocuparam-se com, por exemplo, atividades manuais. Enquanto desenvolviam-nas, discutiam e entravam em contato com os temas propostos. Esse tipo de trabalho tinha intuito de lhes aguçar o senso crítico acerca das questões ambientais. Todavia, procurou-se respeitar ao máximo a cultura e os costumes de cada aluno, sem conflitar o conhecimento familiar e cotidiano deles, com o que lhes foi apresentado, a exemplo do que propôs Paulo Freire (BRANDÃO, 1981) e como sugerem os Parâmetros Curriculares Nacionais (PCNs) (BRASIL, 1998).
As atividades desenvolvidas nos encontros foram divididas em seis etapas:

1) No primeiro encontro avaliou-se o conhecimento prévio dos alunos em relação aos temas programados para a execução do projeto, importante para planejar as atividades que se seguiriam, de acordo com a capacidade dos estudantes. Não se tratou de uma avaliação tradicional. Foi realizada uma oficina de criação de cartazes, em que a turma foi dividida em grupos. Cada qual recebeu um dos temas citados acima para confeccionar cartazes. No final da atividade os grupos revelaram os temas para os quais foram designados, explicaram para seus colegas os objetivos almejados durante o trabalho e apresentaram os cartazes (Figura 1).

2) Do segundo ao quarto encontro, com os alunos mais afeiçoados aos propósitos do projeto, lhes foi solicitado que cada um desenhasse um mapa com o trajeto casa-escola que costumavam percorrer, com indicação no desenho daquilo que lhes chamava atenção no caminho. Em seguida, utilizando fotos aéreas do bairro, pediu-se que indicassem os locais que consideravam importantes nas proximidades da escola. Dentre os lugares citados, estão o colégio, o parque Jardim Botânico e os campi Centro Politécnico e Jardim Botânico, da UFPR. Com os pontos indicados $e$ as imagens em mãos, foi proposta a seguinte situação: "se um
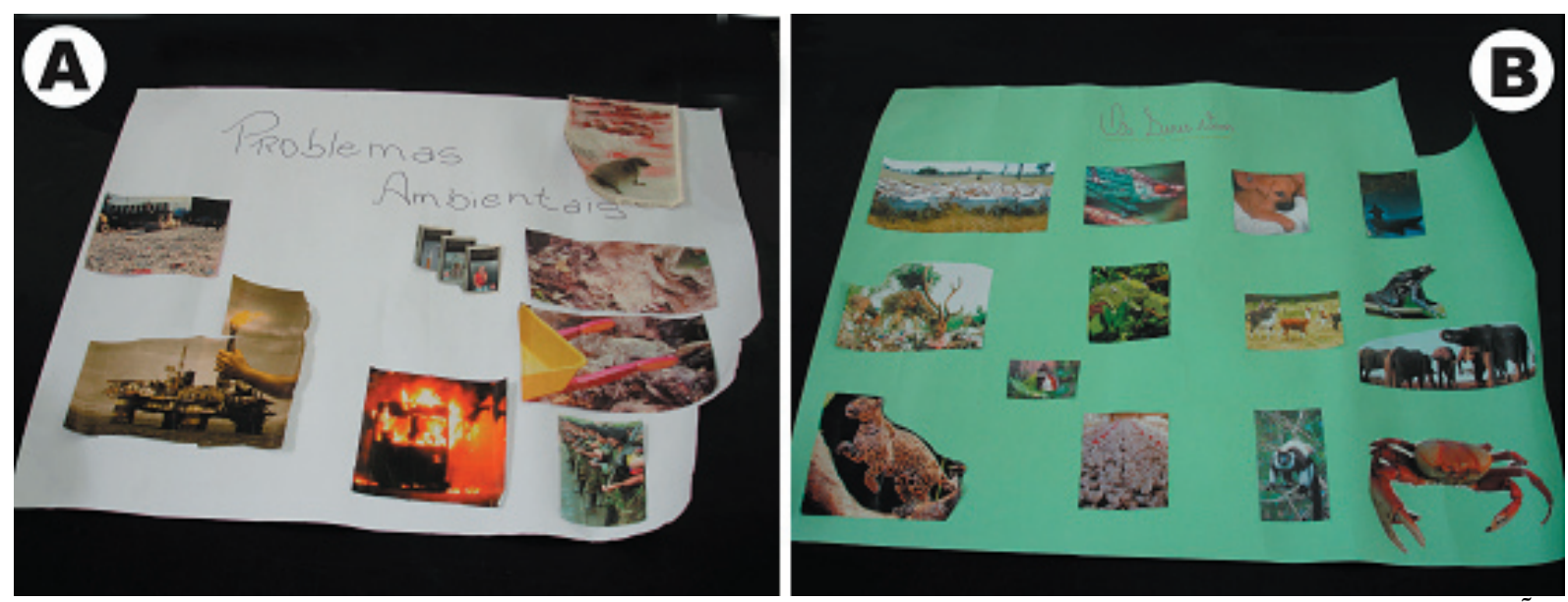

FIGURA 1AE 1B - EXEMPLOS DE CARTAZES CONFECCIONADOS PELOS ESTUDANTES NA AVALIAÇÃO INICIAL. 
extraterrestre quisesse lhe visitar em sua casa, como você indicaria o local?". Foram então exibidas imagens que localizavam a Terra, o Brasil, o Paraná, Curitiba e o bairro Jardim Botânico. Esta atividade permitiu trabalhar com a sensibilidade e localização no espaço cotidiano. Posteriormente os alunos discutiram e confeccionaram maquetes simplificadas, representando a cidade de Curitiba e sua organização (Figura 2). Com essas atividades, os alunos conseguiram se localizar no espaço $e$, com a maquete, interpretar o meio em que vivem.

3) O tema lixo foi apresentado de modo a observar como os alunos reagiriam se o meio em que vivem fosse poluído. No quinto encontro, despejou-se material reciclável e orgânico na sala de aula. Alguns se sentiram incomodados ao verem que o local em que passavam boa parte do dia estava sujo. Outros, porém, não deram atenção ao fato. Realizou-se, então, a limpeza da sala, com a separação para reciclagem do lixo, destinação do material orgânico, com análise das conseqüências da poluição e quais seriam as melhores formas de tratar o lixo.

4) No sexto e sétimo encontros a turma visitou o bosque do parque Jardim Botânico e o Museu de Ciências Naturais da UFPR (Figura 3), sendo conduzida pelos integrantes do projeto $e$ pelos monitores do parque e do museu. Nessa ocasião, tiveram contato com a diversidade de formas de vida existentes no planeta, com destaque ao fato de que constataram, no bairro em que estudam, a existência de
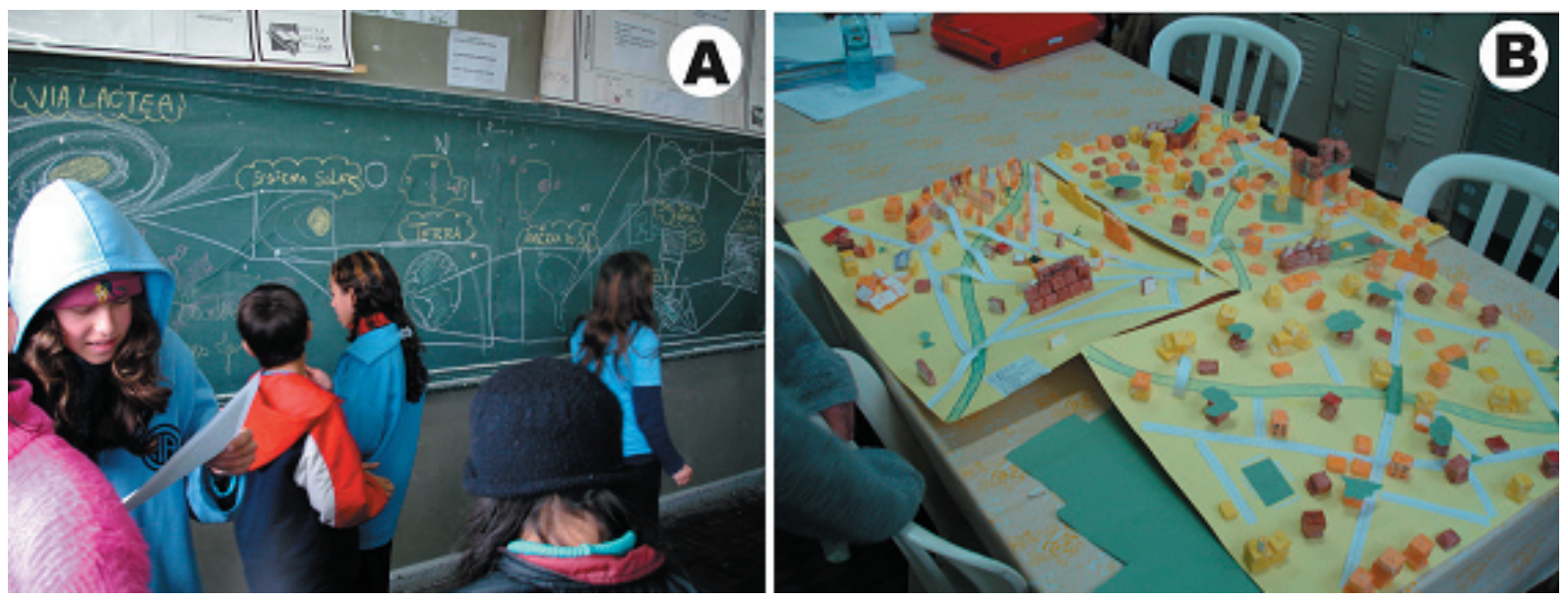

FIGURA 2A - ALUNOS LOCALIZANDO-SE NO ESPAÇO E2B - MAQUETES, REPRESENTANDO CURITIBA, CONFECCIONADAS APÓS A CONCLUSÃO DA ATIVIDADE
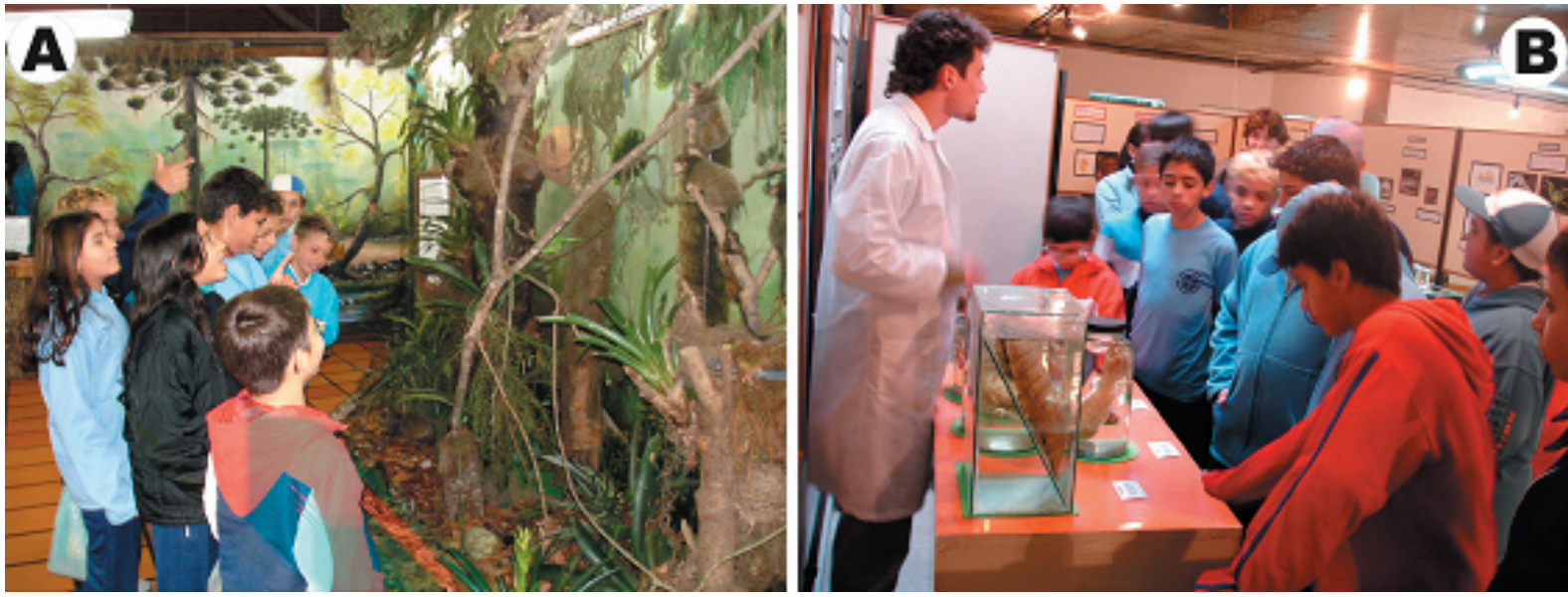

FIGURA 3A - VISITA AO PARQUE JARDIM BOTÂNICO E 3B: AO MUSEU DE CIÊNCIAS NATURAIS DO SETOR DE BIOCIÊNCIAS DA UFPR 
meios naturais relativamente preservados, com grande diversidade biológica. Embora situados próximos da escola, alguns dos alunos ainda não conheciam os locais visitados.

Para reafirmar e avaliar os conceitos adquiridos até essa fase, no oitavo encontro a turma foi novamente dividida em grupos, para um jogo de perguntas e respostas sobre o que foi exposto até então no projeto. O jogo foi disputado com bastante interesse e o grupo que venceu, o fez por uma diferença de um ponto. Tal resultado demonstra que os estudantes assimilaram bem os conceitos apresentados.

5) No nono encontro discutiu-se a importância dos ciclos naturais, como da água e
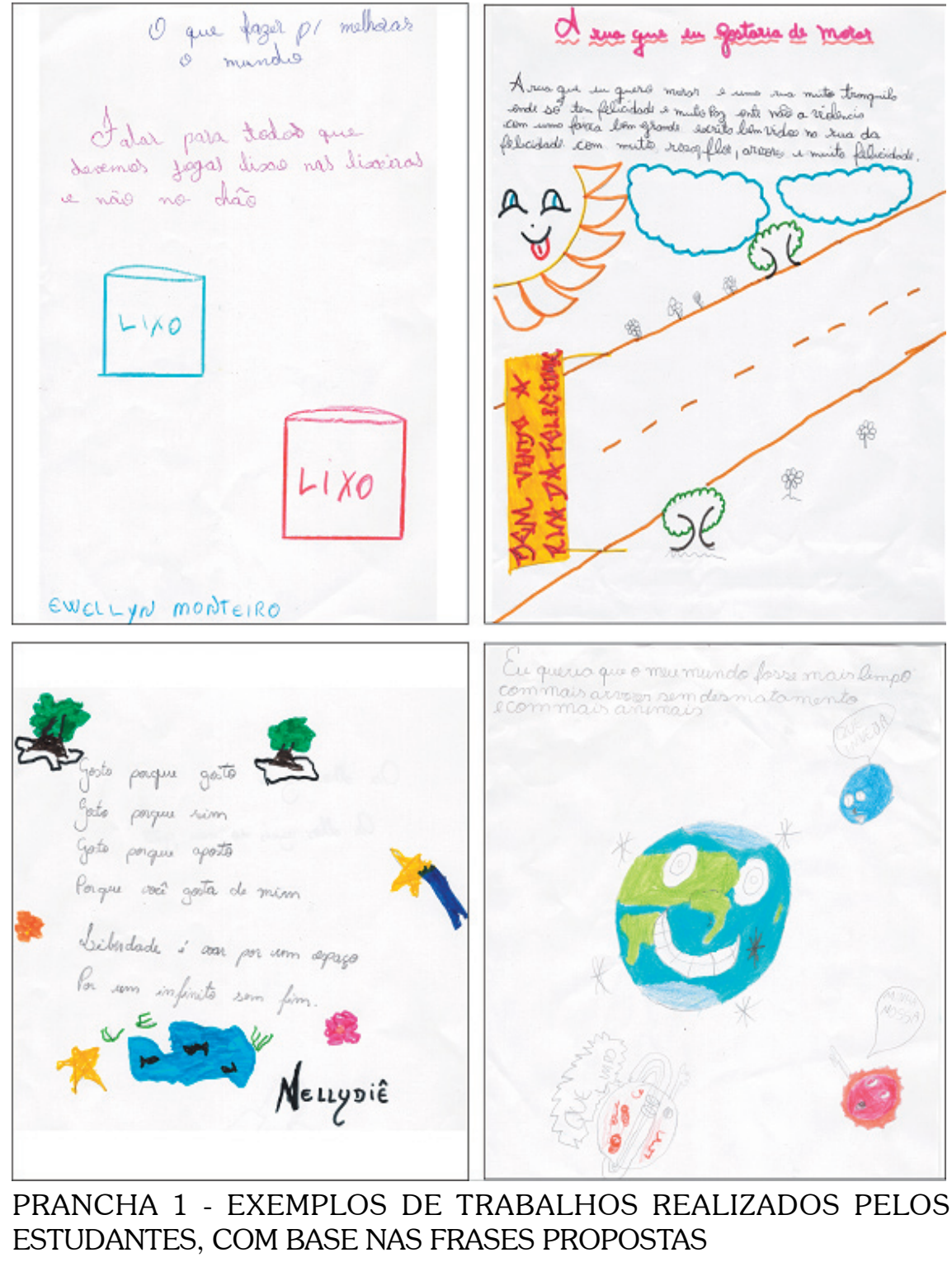

PRANCHA 1 - EXEMPLOS DE TRABALHOS REALIZADOS PELOS ESTUDANTES, COM BASE NAS FRASES PROPOSTAS do carbono para a manutenção da vida na Terra. Ainda sobre os temas, no décimo encontro, a turma assistiu a uma palestra sobre os atuais problemas ambientais e sociais do planeta.

6) A atividade final do projeto, visando também elevar a autoestima dos estudantes, consistiu na confecção de desenhos e/ou textos, sobre as frases: a rua onde eu gostaria de morar, nosso planeta, e o que fazer para melhorar o mundo (Prancha 1). Os alunos foram fotografados e, em pequenas entrevistas, contaram um pouco das suas vidas para os executores do projeto. Isso ocorreu no décimo primeiro e décimo segundo encontros. $\mathrm{O}$ objetivo, além da atividade reflexiva implícita,

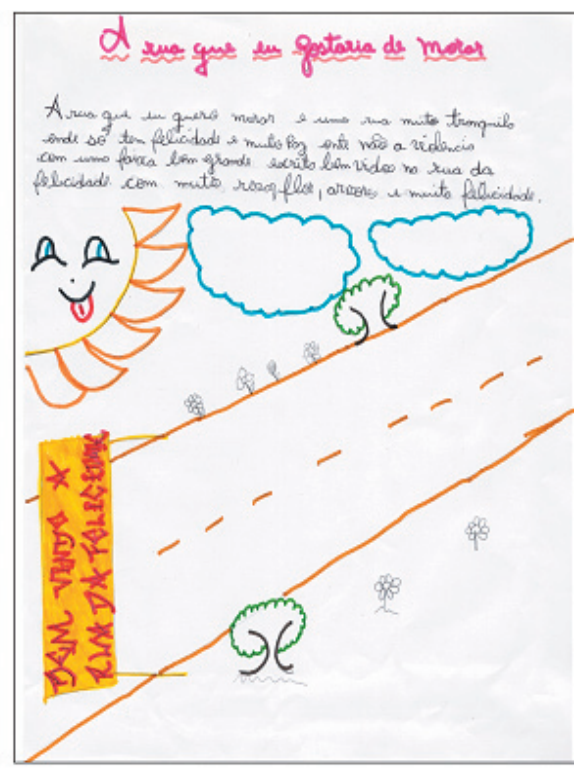


foi produzir livretos como forma de memória dos participantes do projeto (Figura 4).

Concluídas as atividades, no décimo terceiro encontro a turma plantou muda de árvores no gramado do colégio, entregou-se um conjunto com muda de árvores, o livreto, panfletos sobre conservação do meio ambiente e, numa festa destinada aos alunos, houve "seção de autógrafos" do livreto.

\section{Discussão e conclusões}

As atividades coletivas, como confecção de cartazes, maquetes e jogos em grupo, auxiliaram na mudança de comportamento dos alunos, aumentando sua sociabilidade. Notou-se, ainda, aumento da atenção $e$ respeito aos instrutores, assim como disposição para participar das atividades. Inicialmente essa foi a principal dificuldade à execução das atividades planejadas. Outra dificuldade inicial foi o controle do comportamento dos alunos em sala, que se mostravam ansiosos $e$ irrequietos. Aparentemente, uma das razões desse comportamento decorre do fato de que os encontros foram baseados em atividades $e$ modos de condução de tarefas não usuais no cotidiano da turma.

Vencidos os obstáculos iniciais, os estudantes tornaram-se cada vez mais dispostos e participativos. Constatou-se que sua capacidade para absorver o conteúdo exposto era alta. Nas avaliações, ficou explícito que assimilaram o conhecimento apresentado e discutido, além de demonstrarem formação de opinião própria acerca dos temas tratados.

Constatou-se, na experiência realizada, a necessidade de incentivo ao treinamento e à formação continuada de professores da rede

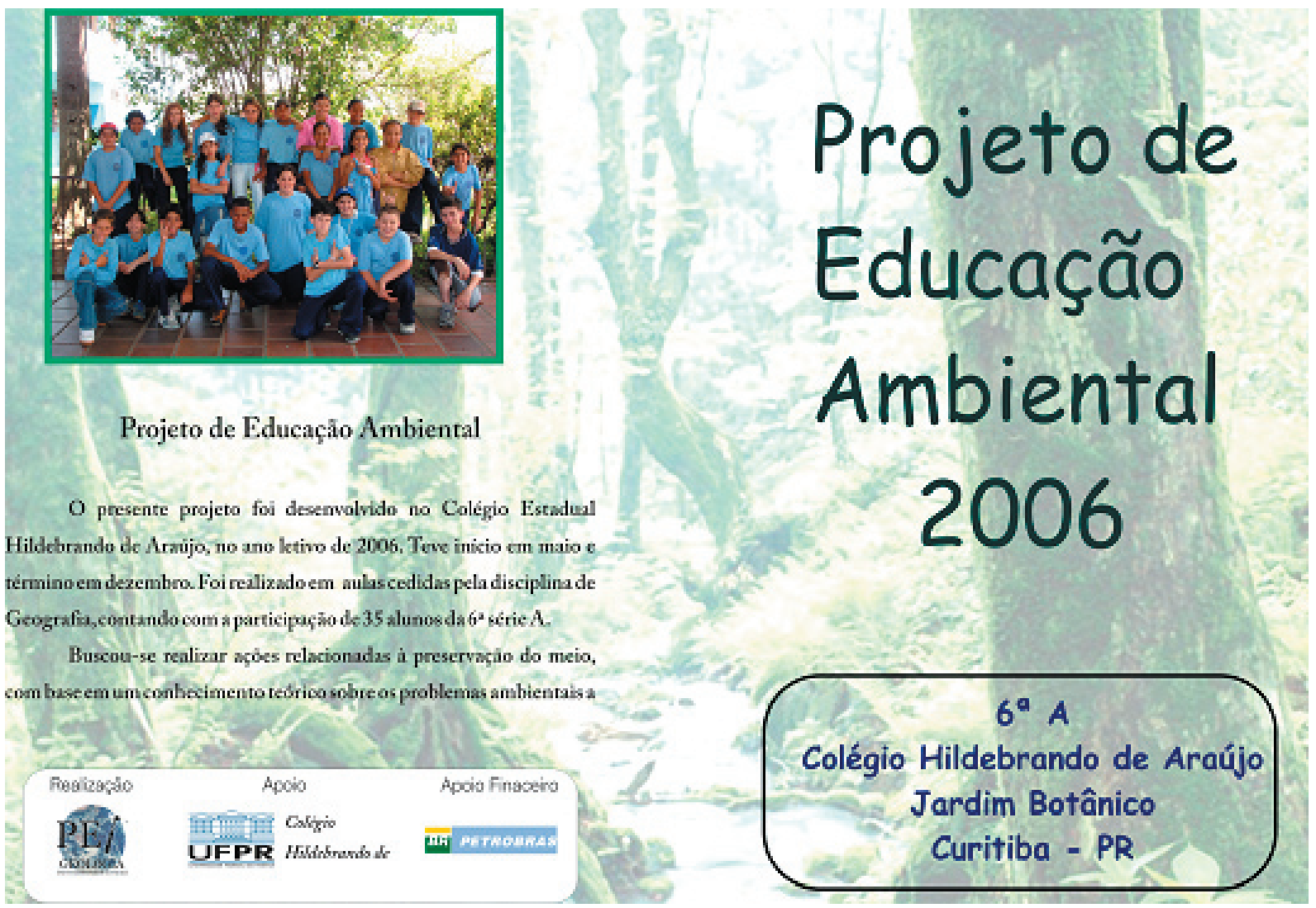

FIGURA 4 - CAPAS EXTERNAS DO LIVRETO-MEMÓRIA QUE FINALIZOU O PROJETO. CONTÉM DESENHOS, TEXTOS, FOTOS DOS ALUNOS E HISTÓRICO DO TRABALHO (PET-GEOLOGIA, 2006) 
pública, sobretudo em temas de Geociências e questões ambientais.

$\mathrm{O}$ acesso à informação de qualidade, sensibilização para problemas ambientais $e$ desenvolvimento de espírito crítico devem ser incentivados. Em geral, a principal fonte de informações dos alunos é a mídia televisiva comercial, que fornece pouca informação e reflexão sobre meio ambiente. A escola também colabora, com tal formação, embora de modo insuficiente. $\mathrm{O}$ acesso dos alunos a essas informações é raro, pois não possuem hábito de leitura e as famílias geralmente não têm condições de contribuir na educação, em temas relativos ao à degradação da natureza. A criação de materiais didáticos e a multiplicação de atividades educacionais específicas para o tema, contribuiriam para a redução do problema.

Foram encontradas dificuldades relacionadas aos conteúdos de cartografia $e$ localização espacial dos alunos. Muitos não sabem localizar o país no mapa da América do Sul, nem o Paraná no contexto nacional. No entanto, em escalas maiores como a do bairro em que vivem, conseguiam identificar vários pontos de referência como supermercados, parques e a escola. Este fato é preocupante, pois, segundo as Diretrizes Curriculares do Estado do Paraná (DCEs-PR) para o ensino fundamental "o aluno deverá ser capaz de transitar entre diferentes escalas espaciais da realidade, desde o cotidiano, expresso no âmbito local, até o global" (PARANÁ, 2005). Dessa forma, é primordial inserir mais atividades que ampliem esta noção escalar no ensino fundamental.

Outro fato verificado foi a visão que apresentam da reciclagem, como fonte de renda sem qualquer relação com os problemas ambientais. Durante a execução das atividades, essa noção foi modificada, com a compreensão de que, além de uma fonte de renda, a reciclagem é necessária à proteção e uso racional dos recursos naturais.

O desenvolvimento do projeto aumentou a sensibilidade, conhecimento ecológico e de noções de cidadania dos estudantes. Criaram-se oportunidades didáticas de identificação, análise e compreensão de problemas socioambientais regionais. Houve boa assimilação de conceitos básicos de Geociências e meio ambiente, reduzindo o déficit de conteúdo nas áreas. Os recursos audiovisuais e lúdicos empregados foram fundamentais na obtenção dos resultados. Esses recursos permitiram que a apresentação e assimilação de conhecimento ocorressem de modo fácil e agradável.

\section{Agradecimentos}

Esse relato constitui uma reflexão de experiência educacional do grupo PETGeologia UFPR, a partir da execução de projeto de extensão universitária (UFPR, 2007), desenvolvido pelos então integrantes do grupo: Anderson L. G. Belem, Bárbara Carolina Dressel, Bruno W. Jeiss, Eduardo Roemers de Oliveira, Fábio Maciel Pinto, Felipe Brasil Felício, João Eloi Dums, Juliana Costa, Júlio César Botega do Carmo, Maiuly Vial Gomes, Manuelle Lago Marques, Marcell Leonard Besser, Rosane dos Santos, Wesley Andersen Mezine e pelo professor tutor Luiz Alberto Fernandes. Agradecemos aos que participaram e à PETROBRAS, pelo apoio financeiro para aquisição de materiais necessários ao desenvolvimento do projeto, assim como para a melhoria da infraestrutura do PET-Geologia. 


\section{REFERÊNCIAS}

BRANDÃO, C. R. O que é método Paulo Freire. São Paulo: Brasiliense, 1981. 114p.

BRASIL. Secretaria de Educação Fundamental. Parâmetros curriculares nacionais: História/Geografia. Brasília: Ministério da Educação, 1998. 128p.

JUK, K. F. V. et al. Educação ambiental para ensino médio e fundamental. A experiência do Grupo PET-Geologia UFPR. In: CONGRESSO BRASILEIRO DE GEOLOGIA, 43, 2006, Aracaju. Anais... 2006, v. 1, p. 196.

MATZ-ARAUJO, M. et al. Projeto Geologando: a atuação dos alunos de graduação em Geologia na divulgação das Geociências para a sociedade. In: CONGRESSO BRASILEIRO DE GEOLOGIA, 43, 2006, Aracaju. Anais... 2006, v. 1, p. 202.

MOTA, S. Urbanização e Meio Ambiente. Rio de Janeiro: ABES, 1999. 352 p.

MESQUITA, M. J. M. et. al. Educação ambiental com alunos carentes do ensino médio em Rio Branco do Sul,
Paraná. In: CONGRESSO BRASILEIRO DE GEOLOGIA, 43, 2006, Aracaju. Anais... Sociedade Brasileira de Geologia, 2006, v. 1, p. 195.

NUCCI, J. C. Análise sistêmica do ambiente urbano, adensamento e qualidade ambiental. Puc-Sp Ciências Biológicas e do Ambiente, São Paulo, v. 1, n. 1, p. 7388, 1999.

PARANÁ. Secretaria de Estado da Educação. Diretrizes Curriculares da educação fundamental da rede de educação básica do Estado do Paraná. Curitiba: 2005. $224 \mathrm{p}$.

PET-GEOLOGIA UFPR - Programa de Educação Tutorial. Projeto de educação ambiental 2006. Curitiba: Universidade Federal do Paraná/PET-Geologia UFPR, 2006. 64p.

UNIVERSIDADE FEDERAL DO PARANÁ. Pró-reitoria de extensão e cultura. Educação ambiental sobre centros urbanos para ensino médio. Projeto 399/06-PROEC, relatório final. 2007. 12p. Inédito.

Texto recebido em 29 de novembro de 2007. Texto aprovado em 15 de dezembro de 2008 